\title{
Low risk of seizure recurrence after early withdrawal of antiepileptic treatment in the neonatal period
}

Lena Hellström-Westas, Gösta Blennow, Magnus Lindroth, Ingmar Rosén, Nils W Svenningsen

\begin{abstract}
The risk of seizure recurrence within the first year of life was evaluated in infants with neonatal seizures diagnosed with a combination of clinical signs, amplitudeintegrated electroencephalogram (EEG) monitoring, and standard EEG. Fifty eight of $283(4.5 \%)$ neonates in tertiary level neonatal intensive care had seizures. The mortality in the infants with neonatal seizures was $36 \cdot 2 \%$. In 31 surviving infants antiepileptic treatment was discontinued after one to 65 days (median 4.5 days). Three infants received no antiepileptic treatment, two continued with prophylactic antiepileptic treatment. Seizure recurrence was present in only three cases $(8 \cdot 3 \%)$ - one infant receiving prophylaxis, one treated for 65 days, and in one infant treated for six days. Owing to the small number of infants with seizure recurrence, no clinical features could be specifically related to an increased risk of subsequent seizures. When administering antiepileptic treatment, one aim was to abolish both clinical and electrographical seizures. Another goal was to minimise the duration of treatment and to keep the treatment as short as possible.

It is suggested that treating neonatal seizures in this way may not only reduce the risk of subsequent seizure recurrence, but may also minimise unnecessary non-specific prophylactic treatment for epilepsy.

(Arch Dis Child 1995; 72: F97-F101)
\end{abstract}

Keywords: neonatal, seizures, EEG, antiepileptic treatment.

Department of

Paediatrics

L Hellström-Westas

G Blennow

$M$ Lindroth

N W Svenningsen

Department of Clinical Neurophysiology I Rosén

Neonatal Intensive Care Unit, University Hospital, Lund, Sweden

Correspondence to: Dr Lena Hellström-Westas, Department of Paediatrics, University Hospital, S-221 85 Lund, Sweden.

Accepted 19 October 1994 cases the possible adverse effects of continuing prophylactic treatment for several months may well be greater than any benefit. ${ }^{4}$ Accordingly, the duration of treatment should be minimised and determined from case to case.

For routine monitoring of patients at increased risk of cerebral complications such as seizures, we use continuous single-channel amplitude-integrated electroencephalograms (aEEG). In this way many types of seizures can be diagnosed - repetitive (clinical or subclinical), solitary, or occurring in combination with subtle symptoms - though some extremely brief seizures or solitary subclinical seizures may be missed. ${ }^{5}$ The effect of antiepileptic treatment on seizure frequency and duration can also be monitored with this technique.

The aim of the present study was to investigate (1) the risk of seizure recurrence within the first year of life after neonatal seizures in a high risk neonatal intensive care population, and (2) whether the routine procedure of stopping antiepileptic treatment early after established seizure is associated with a high risk of seizure recurrence.

\section{Methods}

From 1 January 1990 to 31 December 1991, 1283 patients were treated at our neonatal intensive care unit, a tertiary level facility. Neonatal seizures were diagnosed in $58(4.5 \%)$ of the infants up to 46 weeks' postconceptional age. Another 25 newborn infants with suspected seizures did not fulfil the criteria, and were not included in the study.

Of the 58 infants, 33 were outborn and 25 inborn: 27 were preterm (mean gestational age 29 weeks (range 24-36) and mean birthweight $1415 \mathrm{~g}$ (range 570-4960)) and 31 full term (mean gestational age 39 weeks (range 37-42) and mean birth weight $3420 \mathrm{~g}$ (range 2290-4585)). Initial mortality (death before first discharge from hospital) was $36 \cdot 2 \%$ (21/58) overall, $51.9 \%$ in the preterm subgroup and $22.6 \%$ in the full term subgroup.

Follow up data were obtained from clinical records in survivors at a mean age of 19 months (range 12-31). Only one infant was lost to follow up, a preterm survivor whose family moved to another part of Sweden.

Figure 1 shows aetiology of the seizures, as well as the mortality and seizure recurrence for the different subgroups. Haemorrhagic or ischaemic lesions and birth asphyxia were the most common causes of neonatal seizures. The second largest subgroup of infants was heterogenous, and no clear aetiology for the 


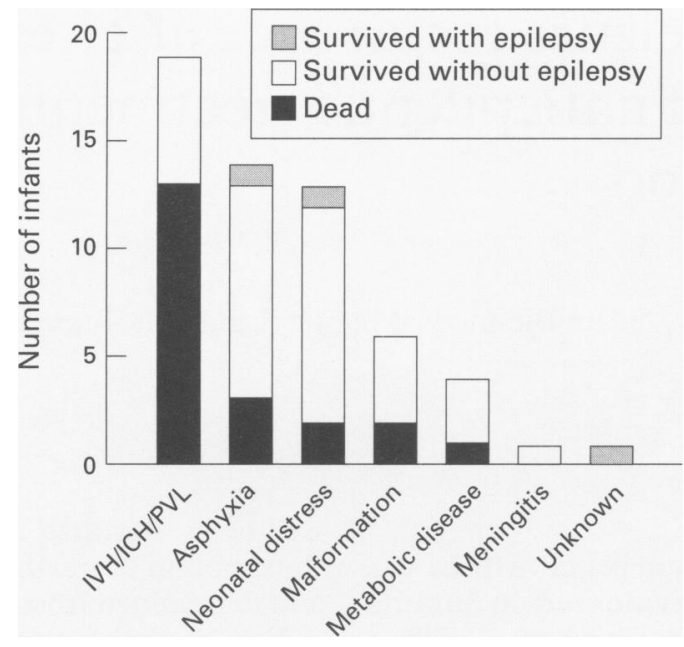

Figure 1 Aetiology of neonatal seizures, in relation to mortality and seizure recurrence, within the first year of life in a neonatal intensive care population.

$I V H=$ intraventricular haemorrhage; $I C H=$ intracranial haemorrhage; $P V L=$ periventricular leucomalacia.

seizures was found. However, the infants all had neonatal distress, such as respiratory distress syndrome, persistent fetal circulation, meconium aspiration syndrome, septicaemia and cardiac malformations. Another six infants had seizures associated with malformations or chromosomal abnormalities (cerebral malformations (two infants), trisomy 18 , incontinentia pigmentii (two infants), congenital adrenal hypoplasia). In four infants the cause of seizures was metabolic disturbances (hypocalcaemia, hypoglycaemia, liver failure, and ornithine transcarbamylase-deficiency). One infant had unprovoked seizures of unknown cause.

Since the $1980 \mathrm{~s}$ it has been routine procedure at our unit to use continuous aEEG monitoring in all cases of infants manifesting clinical signs which could conceivably be compatible with seizures. The aEEG technique has been described in detail elsewhere. ${ }^{56}$ Briefly, with the aEEG monitor (Cerebral Function, CFM Devices Ltd), single-channel biparietal signals are filtered, amplitude integrated, and written out, cotside, on slow speed paper ( 6 or $30 \mathrm{~cm} /$ hour $)$. In the present series of 58 infants the median duration of aEEG monitoring was 67.5 hours (range 3-294).

Standard EEGs were performed during the neonatal period in $94 \%(29 / 31)$ of the full term infant (the two exceptions being due to early death), with a mean of two per infant (range one to seven), and in $33 \%(9 / 27)$ of the preterm infants, with a mean of two per infant (range one to four). Of the 18 preterm infants in whom no standard EEG was performed, 12 died within 11 days of birth mainly due to intracranial or intraventricular haemorrhage (ICH or IVH).

CRITERIA FOR NEONATAL SEIZURE DIAGNOSIS Diagnosis was based on the presence of any of the following: (1) standard EEG with a seizure pattern (lasting at least five to 10 seconds), with or without accompanying clinical seizures $(n=9) ;(2)$ single or a few clinical seizures with corresponding typical seizure pattern at aEEG $(n=20)$; (3) repetitive clinical seizures with or without corresponding seizure pattern at aEEG ( $n=2)$; or (4) repetitive seizure pattern in the aEEG lasting more than 30 minutes with or without concomitant clinical seizures $(n=27)$. In the latter group six preterm infants had subclinical seizures only; 21 infants had both clinical and subclinical seizures.

\section{ANTIEPILEPTIC TREATMENT}

The primary drug used for neonatal seizures was usually phenobarbital (initial dosage $10-20 \mathrm{mg} / \mathrm{kg}$ ), and if there was no response, diazepam (repeated doses of $0.5 \mathrm{mg} / \mathrm{kg}$ ). If these drugs failed lidocaine was added (initial dosage $2 \mathrm{mg} / \mathrm{kg}$ followed by intravenous infusion $4-6 \mathrm{mg} / \mathrm{kg} /$ hour, tailed off within two to 3 days). ${ }^{6}$ If seizure control was not obtained phenytoin (initial dosage $15 \mathrm{mg} / \mathrm{kg}$ ) and in some cases pyridoxin $(100 \mathrm{mg})$ was given.

The mode of withdrawal of antiepileptic treatment was similar in most cases (fig 2). As soon as clinical control of seizures was achieved and EEG or aEEG showed an absence of a seizure pattern, antiepileptic treatment was phased out over a period ranging from a few days to three weeks, phenobarbital being the last drug to be withdrawn. During drug withdrawal all infants were monitored clinically by trained nurses and by aEEG to detect any seizure relapse.

If the first standard EEG was normal and the infant had had only a few seizures antiepileptic treatment was withdrawn and EEG was not repeated. If the initial standard EEG was abnormal, showing either interictal epileptiform activity, seizure patterns, or major abnormalities in the background activity, a second standard EEG was usually performed within a week. If this was normal and the infant had been without antiepileptic treatment for some days, follow up was scheduled from case to case. In cases of infants with recurrent seizures during the initial antiepileptic treatment, EEG was repeated once or twice within two weeks. Antiepileptic treatment was continued if an infant had relapse of seizures during the initial drug withdrawal or if the EEG at any time showed recurrent seizures or multiform epileptiform activity resembling hypsarrhythmia.

Fisher's exact test was used for group comparisons, values of $<0.05$ being considered significant.

\section{Results}

Of the 36 surviving infants, two were receiving prophylactic antiepileptic treatment for more than 65 days, and 31 were treated for one to 65 days (median 4.5 days, with only two infants being treated more than 20 days) and three received no antiepileptic treatment.

Of the 34 infants without prophylactic antiepileptic treatment, two (5.9\%) had recurrence of seizures during the first year of life. One of them was a preterm infant of 26 weeks' gestation who survived with brain damage after fungal septicaemia and seizures in the neonatal period. $\mathrm{He}$ was initially treated with 


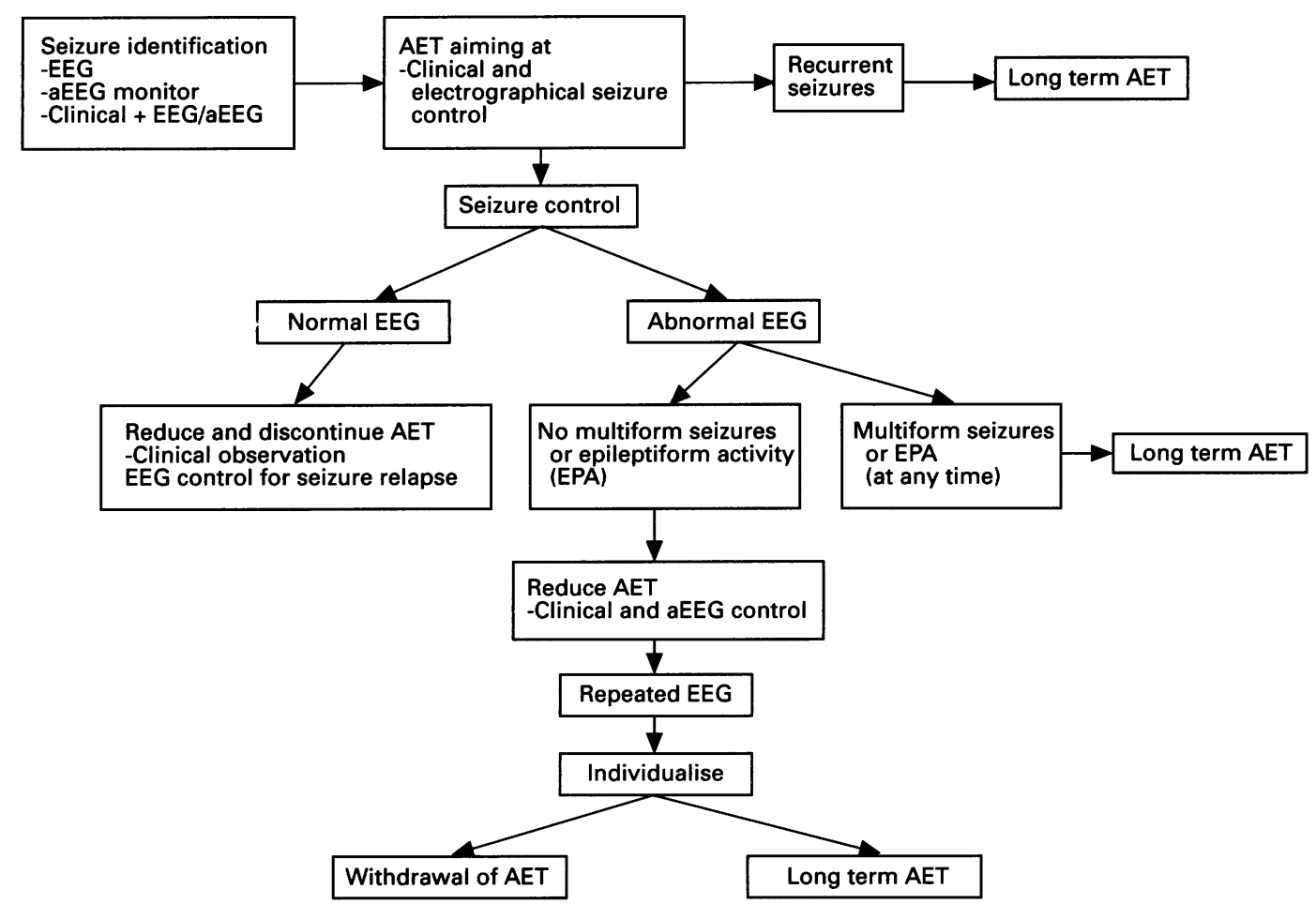

Figure 2 Diagnostic criteria and management of neonatal seizures, including antiepileptic treatment drug withdrawal procedures as applied in this study.

antiepileptic treatment for six days. At 7 months of age, he was readmitted with severe malnutrition and signs of physical abuse. At 10 months he developed epilepsy. The other infant with recurrent seizures was a girl, born at term after an uneventful pregnancy. On her eighth day of life, seizures of unknown cause emerged, the EEG showing continuous multiform seizure activity. Clinical control of her seizures was obtained within a few days. Repeated EEGs were normal and antiepileptic treatment was stopped after 65 days. At 3 months of age, the EEG showed focal epileptiform activity in the right frontal region, but she had no clinical seizures until three months later. Both the EEG and clinical condition deteriorated despite the reintroduction of antiepileptic treatment. At 6 months of age, she developed infantile spasms with hypsarrhythmic EEG and obvious signs of hemiplegia.

Number of neonatal seizures versus mortality; in surviving infants postneonatal seizure recurrence versus findings in neonatal CNS imaging and neonatal EEG

\begin{tabular}{|c|c|c|c|c|c|}
\hline & \multicolumn{5}{|c|}{ Number of infants } \\
\hline & Survivors & & Died & Total & p Value \\
\hline $\begin{array}{c}\text { Neonatal seizures } \\
>10 \text { Seizures } \\
\leqslant 10 \text { Seizures }\end{array}$ & $\begin{array}{l}36 \\
18 \\
18\end{array}$ & & $\begin{array}{r}21 \\
18 \\
3\end{array}$ & $\begin{array}{l}57^{\star} \\
36 \\
21\end{array}$ & $(=0.006)$ \\
\hline Postneonatal seizure recurrence & $\begin{array}{l}\text { Yes } \\
(n=3)\end{array}$ & $\begin{array}{l}\text { No } \\
(n=33)\end{array}$ & & & \\
\hline Infants with neonatal seizures $(n=36)$ & & & & & $(=0.229)$ \\
\hline $\begin{array}{l}>10 \text { Seizures } \\
\leqslant 10 \text { Seizures }\end{array}$ & $\begin{array}{l}3 \\
0\end{array}$ & $\begin{array}{l}15 \\
18\end{array}$ & & & \\
\hline Neonatal CNS imaging $(n=31)$ & & & & & $(=0.576)$ \\
\hline $\begin{array}{l}\text { Abnormal } \\
\text { Normal }\end{array}$ & $\begin{array}{l}1 \\
2\end{array}$ & $\begin{array}{l}16 \\
12\end{array}$ & & & \\
\hline Neonatal EEG $(n=30)$ & & & & & \\
\hline $\begin{array}{l}\text { Seizure activity or EPA } \\
\text { No seizure activity or EPA } \\
\text { Abnormal background activity } \\
\text { Normal background activity }\end{array}$ & $\begin{array}{l}3 \\
0 \\
3 \\
0\end{array}$ & $\begin{array}{l}10 \\
17 \\
14 \\
13\end{array}$ & & & $\begin{array}{l}(=0.141) \\
(=0.335)\end{array}$ \\
\hline
\end{tabular}

*One infant was lost to follow up (see text). CNS imaging=ultrasonography computed tomography, or magnetic resonance imaging; $\mathrm{EPA}=$ interictal epileptiform activity.
One of the two infants receiving prophylactic antiepileptic treatment for more than 65 days, a girl born at term with severe birth asphyxia, developed epilepsy despite prophylactic antiepileptic treatment. Multifocal epileptiform activity was seen in the EEG (which was initially iso-electric) during the first month of life. She survived with postasphyctic brain damage and epilepsy.

The table shows mortality and seizure recurrence in relation to the number of neonatal seizures, and findings at neonatal central nervous system imaging and EEG in the survivors. The survival rate was higher in the subgroup with 10 or fewer neonatal seizures than in the subgroup with more than $10(86 \%$ $(18 / 21)$ vs $50 \%(18 / 36), p=0.006)$. The three survivors with postneonatal seizures all had more than 10 neonatal seizures, but seizure recurrence was unrelated to the number of neonatal seizures.

Of the 36 survivors, 31 underwent cranial ultrasound, computed tomography, or magnetic resonance imaging in the neonatal period. Abnormalities of the brain were diagnosed in 17 infants. In two of the three infants with subsequent seizure recurrence no brain abnormality was evident in the neonatal period. Thus seizure recurrence was not significantly related to the presence of structural changes in the brain $(p=0.576)$, nor to either epileptiform activity or major abnormalities of EEG background activity at any time during the first 30 days after the primary seizure $(p=0.141$ and $p=0.335$, respectively).

\section{Discussion}

Although prophylactic antiepileptic treatment has long been established treatment after neo- 
natal seizures, in recent years its benefits have been questioned, both regarding its efficacy and the possible hazards of prolonged use. ${ }^{349}$

For some years we have tried to reduce and withdraw the antiepileptic treatment in most newborns as early as possible, and managed during the first few days to establish seizure control, with close clinical surveillance, continuous aEEG monitoring, and repeated standard EEG for early detection of seizure relapse. Despite the short duration of antiepileptic treatment (median 4.5 days), only $8.3 \%$ of our patients had seizure recurrence during their first year of life. Moreover, with our current routines two of the three newborn infants who subsequently developed epilepsy were already identified as high risk patients in the neonatal period.

Electroencephalography is a sensitive tool for predicting general outcome and the risk of seizure recurrence after neonatal seizures, a normal EEG indicating a low risk of seizure relapse. ${ }^{1011}$ In the present study no infant with a normal neonatal EEG had seizure recurrence.

Recurrent neonatal seizures over an extended period have been shown to imply an increased risk of epilepsy. ${ }^{2}$ In the present study the three infants with recurrent seizures during the first year of life had all had more than 10 seizures in the neonatal period. Statistically, however, the number of seizures was related only to mortality. Our series was too small to establish risk criteria for seizure recurrence and included very few infants with seizure relapse.

Although diagnosis of neonatal seizures is generally established on clinical signs and symptoms, ${ }^{4}$ most neonatal seizures are characterised by very subtle expression or are entirely subclinical. ${ }^{15-17}$ By including continuous EEG monitoring, more seizures than previously will be diagnosed, ${ }^{18}$ but in population comparisons this does not seem to increase greatly the rate. In 1982 Holden and co-workers ${ }^{2}$ reported an incidence of neonatal seizures of $0.5 \%$ with a mortality of $34.8 \%$ similar to that of the present study, but a higher rate of seizure recurrence $(20 \%$ vs $8 \cdot 3 \%)$. Of our series of 58 newborns with neonatal seizures, 28 were delivered within the primary catchment area out of a total of 11171 live births during the period $1990-91$ - that is, a rate of $0.25 \%$. This is somewhat higher than the rate of $0.15 \%$ in an earlier Swedish population based study from $1979 .{ }^{12}$ Our concomitant clinical observations and EEG monitoring may diagnose a larger proportion of infants, including those with subclinical seizures. None the less as most newborns manifest a combination of both clinical and subclinical seizures, ${ }^{4} 1618$ only minor differences in incidence should result from the EEG monitoring as such. On the other hand, such continuous monitoring will also permit differentiation of epileptic and non-epileptic convulsions - infants with jitteriness or myoclonic movements, for example.

It is reasonable to suppose that the successive improvement in perinatal care over the years will have resulted in a lower incidence of infants with neonatal convulsions in risk populations. Even in studies confined to sick newborns, the seizure rates obtained depend on the diagnostic tools used and the criteria adopted. For instance, in a series of 4020 infants Scher and coworkers, using standard EEG only, obtained a rate of $2 \cdot 3 \% .{ }^{13}$ This is to be compared with the rate of $4.5 \%(58 / 1283)$ in our population, which is none the less low by comparison with that of $20 \%$ obtained in a series of 275 infants by Connell and colleagues using the four channel Medilog-EEG technique for surveillance of a neonatal risk population. ${ }^{14}$

If the EEG is recorded during administration of antiepileptic treatment, some infants will be found to have persisting subclinical seizures despite the abolition of overt clinical seizures. ${ }^{19}$ In the present series we aimed at abolishing both the clinically observed seizures and the electrographic seizures manifest in the continuous aEEG recordings. This might explain why so few infants in the present study had seizure recurrence, despite the short duration of antiepileptic treatment. Both in humans and in animals the immature brain is highly susceptible to seizures. In animal experiments kindling (repetitive subconvulsive electrical stimulation) facilitates recurrent seizures. ${ }^{20}$ Our hypothesis is that rapid reduction of the epileptic stimulus of the neurons, achieved by prompt antiepileptic treatment of both clinical and EEG seizure manifestations, would diminish the kindling effect and the risk of subsequent epilepsy. A clinical consequence would be that continuous EEG monitoring is necessary when using the short but effective treatment periods as we have tried in the present study. This hypothesis should be considered in future clinical trials, preferably designed as multicentre randomised control trials comprising larger series of infants with seizures.

In our mixed population of sick newborn infants the overall risk of later seizure recurrence after neonatal seizures was low $(8 \cdot 3 \%)$. In infants with only a few seizures and a normal EEG (monitored by EEG to check that the infant did not have numerous subclinical seizures), antiepileptic treatment can usually be withdrawn soon after seizure control has been established. In cases of infants with frequent (more than 10) neonatal seizures, in most cases antiepileptic treatment can be withdrawn when the EEG is normal before the patient is discharged. In a few infants with frequent and severe seizures in combination with severely abnormal EEG, longterm prophylactic antiepileptic treatment may still be preferable. In some of these infants the risk of developing epilepsy may still be high despite continued antiepileptic treatment. Although a few patients may develop epilepsy after their first year of life, ${ }^{1}$ this does not justify the use of prophylactic antiepileptic treatment in most cases of neonatal seizures.

This study was supported by grants from the Medical Faculty of Lund University, the Swedish Medical Research Council (grant Nos 4732 and 084), and the Johan and Greta Kock Foundation. 
1 Dennis J. Neonatal convulsions. Aetiology, late neonatal status and long-term outcome. Dev Med Child Neurol 1978; 20: 389-403.

2 Holden KR, Mellits ED, Freeman JM. Neonatal seizures. I. Correlation of prenatal and perinatal events with outcome. Pediatrics 1982; 70: 165-76.

3 Clancy RR, Legido A. Postnatal epilepsy after EEGclancy RR, Legido A. Postnatal epilepsy after EEG-

4 Volpe JJ. Neonatal seizures: Current concepts and revised olpe J. Neonatal seizures: Current concep
classification. Pediatrics 1989; 84: 422-8.

5 Hellström-Westas L. Comparison between tape-recorded and amplitude-integrated EEG monitoring in sick newborn infants. Acta Paediatrica Scandinavica 1992; 81: 812-19.

6 Hellström-Westas L, Westgren U, Rosén I, Svenningsen NW. Lidocaine for treatment of severe seizures in newborn infants. I: Clinical effects and cerebral electrical activity monitoring. Acta Paediatrica Scandinavica 1988; 77: 79-84.

7 Prior PF, Maynard DE. Monitoring cerebral function. Longterm recordings of cerebral electrical activity and evoked potentials. Amsterdam: Elsevier, 1986.

8 Farwell JR, Lee YJ, Hirtz DG, Sulzbacher SI, Ellenberg JH, Nelson KB. Phenobarbital for febrile seizures - effects on intelligence and on seizure recurrence. $N \mathrm{Engl} \mathrm{f} \mathrm{Med}$ 1990; 322: 364-9.

9 Diaz J, Schain RJ. Phenobarbital: effects on long-term administration on behavior and brain of artificially reared rats. Science 1978; 199: 90-5.

10 Rowe KC, Holmes GL, Hafford J, Baboval D, Robinson S, Philipps A, et al. Prognostic value of the electroencephalogram in term and preterm infants following neonatal seizures. Electroencephalogr Clin Neurophysiol 1985; 60: 183-96.

11 Brod SA, Ment LR, Ehrenkrantz RA, Bridgers S. Predictors of success for drug discontinuation following neonatal seizures. Pediatr Neurol 1988; 4: 13-7.

12 Eriksson $M$, Zetterström $R$. Neonatal convulsions. Incidence and cause in the Stockholm area. Acta

13 Scher MS, Aso K, Beggarly ME, Hamid MY, Steppe DA, Painter MJ. Electrographic seizures in preterm and fullterm neonates: Clinical correlates, associated brain lesions, and risk for neurologic sequele. Pediatrics 1993; 91: $128-34$.

14 Connell J, Oozeer R, de Vries L, Dubowitz LMS, Dubowitz V. Continuous EEG monitoring of neonatal seizures: diagnostic and prognostic considerations. Arch Dis Child 1989; 64: 452-8.

15 Eyre JA, Oozeer RC, Wilkinson AR. Diagnosis of neonatal seizure by continuous recording and rapid analysis of the
electroencephalogram. Arch Dis Child 1983; 58: 785-90.

16 Hellström-Westas L, Rosén I, Svenningsen NW. Silent seizures in sick infants in early life. Acta Paediatrica seizures in sick infants in eart

17 Mizrahi EM, Kellaway P. Characterization and classification of neonatal seizures. Neurology 1987; 37: 1837-44. 18 Clancy RR, Legido A, Lewis D. Occult neonatal seizures. Epilepsia 1988; 29: 256-61.

19 Hakeem VF, Wallace SJ. EEG monitoring of therapy for neonatal seizures. Dev Med Child Neurol 1990; 32: 858-64.

20 Moshé S. Epileptogenesis in the immature brain. Epilepsia 1987; 28 (suppl 1): S3-15. 